\title{
Percursos de jovens em contextos de vulnerabilidade social: um estudo longitudinal
}

\section{Journeys of young people in contexts of social vulnerability: a longitudinal study}

\author{
Renata Petry Brondani (orcid.org/0000-0001-7251-1449)1 \\ Camila Almeida Kostulski (orcid.org/0000-0003-3677-0501)2 \\ Joana Missio (orcid.org/0000-0002-0757-7174)3 \\ Fabiana Muller Schmitt (orcid.org/0000-0002-7902-9759)4 \\ Dorian Mônica Arpini (orcid.org/0000-0002-1667-51 12)5
}

\begin{abstract}
Resumo
Este estudo busca compreender os significados atribuídos por jovens em contextos de vulnerabilidade social aos seus percursos de vida. A pesquisa possui caráter qualitativo e foi realizada com cinco jovens que, em 2012, haviam participado de um documentário que abordava as experiências de vida de adolescentes de uma Escola Aberta. A partir dos relatos dos participantes e do caráter longitudinal deste estudo, constatou-se que as experiências de ingresso no mundo adulto marcadas por situações de violências, riscos, contextos excludentes e de vulnerabilidades dificultam a concretização de seus projetos e trazem particularidades para a vivência desse período de transições. Como considerações finais, salienta-se a importância de investimentos em ações que possam superar os atravessamentos das vulnerabilidades, como uma forma de evitar possíveis estigmas que fazem parte de determinados contextos. Ressalta-se a relevância do caráter longitudinal desta pesquisa, uma vez que, ao ter escutado esses jovens em dois momentos distintos, ampliaram-se as possibilidades de compreensão de seus percursos de vida.
\end{abstract}

Palavras-chave: Adolescentes. Jovens. Vulnerabilidade social. Exclusão social.

\footnotetext{
${ }^{1}$ Universidade Federal de Santa Maria, Santa Maria, Brasil. E-mail: renata_pb_@hotmail.com.

2 Universidade Federal de Santa Maria, Santa Maria, Brasil. E-mail: camila.ak@hotmail.com.

3 Universidade Federal de Santa Maria, Santa Maria, Brasil. E-mail: joanamissio@hotmail.com.

4 Universidade Federal de Santa Maria, Santa Maria, Brasil. E-mail: fabianaschmitt@gmail.com.

${ }^{5}$ Universidade Federal de Santa Maria, Santa Maria, Brasil. E-mail: monica.arpini@gmail.com.
} 


\begin{abstract}
This study seeks to understand the meanings attributed by young people in contexts of social vulnerability to their life paths. The research has a qualitative character and was carried out with five young people who, in 2012, had participated in a documentary that addressed the life experiences of adolescents at an Open School. From the report of the participants and the longitudinal character of this study, it was found that the experiences of entering the adult world marked by situations of violence, risks, exclusionary contexts and vulnerabilities hinder the implementation of their projects and bring particularities to the experience of this period of transitions. As final considerations, the importance of investments in actions that can overcome the crossings of vulnerabilities is highlighted, as a way to avoid possible stigmas that are part of certain contexts. The relevance of the longitudinal character of this research is emphasized, since, by having listened to the young people at two different moments, the possibilities of understanding their life paths were expanded.
\end{abstract}

Keywords: Adolescents. Youngsters. Social vulnerability. Social exclusion.

A pluralidade dos modos de viver a adolescência na sociedade contemporânea possibilita que a passagem por esse período seja atravessada por diferentes experiências e contextos. Nesse sentido, as características peculiares da experiência adolescente são amplamente influenciadas pelo ambiente sociocultural em que se dão os diferentes percursos de vida (Arpini \& Witt, 2015; Novaes, 2006; Osório, 1989). Levando em consideração a contextualização das adolescências, pressupõe-se a existência de uma crise psicológica atrelada a uma crise social. Trata-se de um momento, geralmente, perpassado por intensos conflitos e crises nos referenciais, nas perspectivas, na identidade e na personalidade, entrelaçados ao cenário social ao qual pertence (Matheus, 2010). Nessa perspectiva, as "crises" adolescentes podem ser ainda mais difíceis para aqueles que as vivenciam em meio a alguns agravantes, como nos casos de meninos e meninas em situação de vulnerabilidade social.

É importante destacar que não há um consenso sobre a definição de vulnerabilidade social (Carmo \& Guizardi, 2018; Monteiro, 2011), contudo, é possível tecer algumas considerações que permitem compreender aspectos desse conceito. De acordo com Cruz e Hillesheim (2016), a palavra "vulnerável" advém de "vulnerabilis", que, em latim, associa-se à ideia de dano, lesão, perdas. Nessa direção, Castel (1997) pontua a existência de uma "zona 
de vulnerabilidade", na qual os indivíduos se encontrariam com os vínculos sociais fragilizados e com o trabalho precarizado, correndo o risco de adentrar a "zona de desfiliação" (rompimento de vínculos sociais e desemprego). Portanto, entende-se que a vulnerabilidade social não se restringe à pobreza, podendo ser relacionada à ideia de risco frente ao desemprego, à precariedade do trabalho, à pobreza, à falta de proteção social ou acesso aos serviços públicos, à fragilidade dos vínculos afetivos e de pertencimento, decorrentes também das discriminações etárias, étnicas, de gênero, entre outras (Abramovay et al., 2002; Cronemberger \& Teixeira, 2013; Janczura, 2012).

Tendo isso em vista, Abramovay et al. (2002) advertem para a correlação existente entre a condição de vulnerabilidade social em que se encontram os jovens e o abalo no acesso às oportunidades sociais, econômicas e culturais, ou seja, na integração social, sustentando um cenário de violências. Assim, as vulnerabilidades podem estar frequentemente relacionadas às dificuldades de acesso ou ao suporte nos âmbitos familiar, comunitário e/ou social, sendo estes de grande importância para que as transformações da adolescência ocorram de forma mais acolhedora (Arpini, 2003). Se a própria tentativa da construção de seu lugar no mundo e de expressão de suas angústias e desejos coloca os jovens em uma posição vulnerável, então, ainda mais vulneráveis estarão aqueles que experimentam isso em meio a condições sociais adversas (Klautau, 2017). Nesse sentido, é preciso considerar os efeitos da vulnerabilidade social na dimensão subjetiva, uma vez que a pobreza econômica se desdobra em uma pobreza simbólica, e diversos rótulos passam a marcar os sujeitos imersos nesse contexto e inscrevê-los no social (Kemper, 2013; Klautau, 2017).

Dessa forma, pensar sobre a juventude e a adolescência no Brasil nos dias de hoje implica considerar que as marcas deixadas cotidianamente na vida de meninos e meninas pela desigualdade e pela exclusão são frutos de relações assimétricas, históricas, econômicas, políticas e culturais entre os diferentes espaços sociais, gerando vulnerabilidades (Novaes, 2006). Oliveira (2001) retrata essa desigualdade, afirmando que “de um lado, temos uma minoria de brasileiros que 'tão podendo' e [...] de outro lado, existe uma grande maioria de jovens (constituída de negros, pardos e pobres), que têm menos 
chances de se reconhecer nesses padrões" (pp. 39-40). Assim, imersos na miséria, na desigualdade e até mesmo na falta de acesso aos direitos mais básicos, esses jovens se encontram no meio de um conflito com o laço social, que individualiza seus impasses e criminaliza suas saídas (Oliveira, 2001; Rosa, 2016).

Assim, cabe questionar de que forma as vulnerabilidades atravessam os percursos de vida desses jovens. Entrelaçadas às vulnerabilidades que se apresentam, essas histórias de vida possuem como marcas perdas afetivas e materiais, passagens por instituições de acolhimento ou socioeducativas, abandono, diversas violências, circulação por territórios de risco, moradias precárias, experiências escolares difíceis, trabalho precoce e, até mesmo, em alguns casos, envolvimento com o tráfico de drogas (Warpechowski \& De Conti, 2018). A partir disso, Carmo e Guizardi (2018) salientam a necessidade de olhar para a integralidade desses sujeitos, identificando que suas demandas e necessidades são de diversas ordens e estão suscetíveis a riscos nesses contextos. Tendo em vista esses aspectos, o presente artigo tem como objetivo compreender os significados atribuídos por jovens em contexto de vulnerabilidade social aos seus percursos de vida.

\section{Percurso metodológico}

Com o intuito de contemplar os objetivos do estudo, foi realizada uma pesquisa de abordagem qualitativa. Segundo Gaskell (2005), a pesquisa qualitativa fornece dados para a compreensão das relações entre os atores sociais e sua situação, de modo que os fenômenos são compreendidos a partir dos sujeitos envolvidos.

Os participantes desta pesquisa foram os jovens que, no ano de 2012, participaram de um documentário, cujo nome não será citado para que os mesmos não sejam identificados. Esse documentário visava retratar os adolescentes e a escola em que estudavam, por meio de um roteiro de entrevistas que explorava os seguintes aspectos: lembranças da infância, concepções sobre adolescência, projetos futuros, opiniões sobre a escola, sobre suas famílias, sobre seus contextos de vida etc. Após aproximadamente quatro 
anos, esses adolescentes, agora jovens, foram novamente contatados para que fosse possível conhecer e entender aspectos marcantes e significativos de seus percursos de vida nesse intervalo de tempo.

$\mathrm{Na}$ época em que o documentário foi produzido, os participantes eram adolescentes, pois, segundo o Estatuto da Criança e do Adolescente (ECA), a pessoa com idade entre 12 e 18 anos é considerada adolescente (Brasil, 1990). Entretanto, no momento deste estudo, os participantes, em sua maioria, já seriam considerados jovens, sendo que apenas Juliana, quando contatada, possuía menos de dezoito anos. A denominação "jovem" está amparada no Estatuto da Juventude, compreendendo pessoas com idade entre 15 e 29 anos (Brasil, 2013). Tendo em vista esses documentos e as respectivas classificações, ao longo do artigo, será utilizado o termo "jovem" em referência aos participantes dessa etapa da pesquisa.

Integraram este estudo cinco dos jovens que participaram do referido documentário, sendo que um deles não foi contatado pessoalmente, em razão de estar em privação de liberdade. Em função disso, as informações referentes a ele foram obtidas em entrevista realizada com sua avó. Salienta-se que o documentário foi realizado com seis participantes, mas que, para este estudo, foi possível acessar as trajetórias de cinco jovens, pois um deles, apesar de muitas tentativas, não foi localizado.

Na ocasião do documentário, em 2012, os participantes frequentavam uma escola de Ensino Fundamental que funciona na modalidade de Escola Aberta, na qual as pesquisadoras realizam um projeto de extensão. As Escolas Abertas foram criadas visando promover um espaço diferenciado e acolhedor de aprendizagem para crianças e adolescentes que estão fora do sistema educacional tradicional ou que não conseguiram se adaptar em uma escola regular. Tratam-se, portanto, de instituições governamentais que atendem crianças e adolescentes que apresentam defasagem escolar e que foram expostos a diversos fatores de risco durante o seu desenvolvimento. Sendo assim, têm, em suas histórias, dificuldades familiares, uso de drogas, violência doméstica, comportamentos de risco e relações instáveis com a escola regular. Além disso, muitas vezes, apresentam vivência de rua, bem como passagens por instituições de acolhimento e instituições de cumprimento de medidas socioeducativas. Essa modalidade escolar tem seu funcionamento em turno integral, no 
sistema de etapas (cada etapa corresponde a duas séries do Ensino Fundamental), totalizando quatro etapas. As aulas acontecem pela manhã, e no turno inverso ocorrem oficinas pedagógicas de padaria, papel reciclado, serigrafia, cabeleireiro, informática, entre outras.

Como instrumentos para coleta de dados, foram utilizadas entrevistas individuais semidirigidas. Entende-se que o emprego da entrevista em pesquisa qualitativa auxilia a explorar em profundidade os pontos de vista dos entrevistados, pois se constitui como uma técnica que possibilita compreensão detalhada das crenças, atitudes, valores e motivações em relação às vivências dos indivíduos em contextos sociais específicos (Gaskell, 2005).

Destaca-se que, para a efetivação deste estudo longitudinal, as entrevistas foram construídas de forma individualizada, a partir das falas de cada participante no documentário. Para tal, a equipe de pesquisa analisou o documentário e buscou filtrar as especificidades relativas a cada participante. Essa estratégia teve como propósito conectar os dois tempos do estudo, relembrando junto com os participantes as suas colocações quando da realização do documentário. Assim, os roteiros das entrevistas consistiram em duas partes: na primeira, algumas questões gerais para todos os participantes, como: lembranças que possuíam acerca do documentário; lembranças das oficinas com a equipe de psicologia; acontecimentos posteriores à saída da escola; lembranças de sonhos e expectativas que tinham mencionado no documentário; como compreendiam a adolescência nesse período (tempo entre o documentário e a entrevista); aspectos marcantes de seus percursos de vida. Já na segunda parte, foram elaboradas questões específicas para cada jovem, considerando as particularidades trazidas no documentário.

Quanto aos procedimentos, primeiramente, houve a autorização da equipe diretiva da escola onde o documentário foi filmado. Após, a proposta foi aprovada pelo Comitê de Ética da Universidade à qual as pesquisadoras estão vinculadas. A partir disso, os jovens foram contatados via telefone e convidados a participarem da pesquisa. Com o aceite, foram marcadas as entrevistas de acordo com a disponibilidade de cada participante, sendo que 
estas foram realizadas nas dependências da escola. A entrevista que foi realizada com a avó de um dos participantes ocorreu no domicílio da mesma.

A partir das transcrições das entrevistas, realizou-se a análise do material, primeiramente, de forma individual e, depois, por meio de um comparativo entre os depoimentos dos participantes do momento do documentário, em 2012, e a entrevista realizada quatro anos depois, em 2016. Para isso, utilizou-se a análise de conteúdo, que se caracteriza por um conjunto de instrumentos metodológicos aplicados aos discursos, analisando as comunicações, decompondo-as e elencando-as, posteriormente, em categorias (Bardin, 2010).

Ressalta-se que a pesquisa atendeu a todas as exigências éticas em pesquisa, segundo as Diretrizes e Normas Regulamentadoras envolvendo seres humanos - Resolução 510/2016 do Conselho Nacional de Saúde (CNS). O estudo obteve aprovação do Comitê de Ética em Pesquisa da Universidade em que foi realizado, sendo aprovado sob CAAE 61015216.2 .0000 .5346

A fim de melhor contribuir para as discussões propostas, optou-se por apresentar brevemente os percursos dos jovens que integraram este estudo.

\section{Percurso de Karina}

Em 2016, Karina possuía 19 anos e, na época do documentário, tinha 15 anos. Ela é irmã de André, também integrante desta pesquisa. Karina possui o Ensino Fundamental completo, concluindo-o na escola onde o documentário foi realizado. No entanto, não ingressou no Ensino Médio, ainda que demonstrasse grande desejo de cursá-lo. Ela reside com a mãe e dois irmãos, sendo que, na entrevista, relatou dificuldades de relacionamento com ela e com um dos irmãos. O pai de Karina já é falecido. Karina estava planejando mudar-se para outra cidade e ir morar com um tio, principalmente devido aos conflitos com a mãe.

Karina mencionou que frequenta festas e que presenciou alguns episódios de violência, até mesmo com seu irmão, devido, muitas vezes, ao uso de drogas. Além desses 
fatos, a jovem relatou o assassinato de um amigo que lhe era muito próximo, em um bairro da periferia da cidade, reforçando a questão da violência no local em que reside. Tanto no documentário, quanto na pesquisa, referiu que gostaria que ocorressem algumas mudanças no mundo, para que a violência, o uso de drogas e a ingestão excessiva de bebidas alcoólicas pudessem ser minimizados.

\section{Percurso de Juliana}

No momento da gravação do documentário, Juliana tinha 12 anos e, quando ocorreu o contato para a pesquisa, ela encontrava-se com 17 anos. Juliana é irmã de Marcos, que também é um dos participantes. Atualmente, reside com a mãe, o padrasto e dois irmãos, havendo recentemente mudado de bairro.

Desde pequena, Juliana gostava de frequentar a escola e chegou a ingressar no Ensino Médio, porém, não conseguiu dar continuidade aos estudos. Essa dificuldade, segundo a jovem, ocorreu por diversos motivos, dentre eles, o principal foi o rompimento de um relacionamento de três anos, sendo que o término não foi aceito pelo seu ex-namorado, o qual fez ameaças, dificultando a liberdade e autonomia de Juliana e de sua família.

Com esse acontecimento, Juliana não só precisou sair da sua residência, onde, na época, morava com o namorado, como também teve de se mudar de bairro para não ser encontrada por ele. O seu ex-namorado seria uma pessoa influente no bairro onde residiam e a jovem menciona o medo e a insegurança envolvidos ao sustentar o término dessa relação. Dessa forma, refere que o contexto desse relacionamento violento foi determinante para que não pudesse mais frequentar a escola, pois ainda se sente intimidada e constrangida pelo referido rapaz.

\section{Percurso de André}


André é um jovem de 18 anos, sendo que aos 14 anos participou do documentário. Ele concluiu o ensino fundamental na Escola Aberta. Logo que ingressou no Ensino Médio, acabou reprovando, pois faltava às aulas. No entanto, no momento da entrevista, ele encontrava-se frequentando outra escola. André é irmão mais novo de Karina.

Quando questionado sobre o que mudou em sua vida desde o documentário, André relata, com muita tristeza, que um de seus amigos de infância morreu em uma festa. Recentemente, também vivenciou a morte de sua avó, o que fez com que a família de André fosse morar na casa em que a avó residia. Porém, o jovem refere ter uma grande ligação com o antigo bairro em que morava e as pessoas que lá se encontram. No documentário, também relatou que sonhava em morar na favela do alemão, no Rio de Janeiro.

\section{Percurso de Marcos}

Marcos é um jovem de 20 anos e, quando participou do documentário, estava com 15. Marcos é pai de dois filhos e, atualmente, reside em uma casa própria com eles e com sua companheira, referindo considerar-se um bom pai. Sua irmã mais nova, Juliana, também é integrante do presente estudo.

Marcos, quando questionado sobre seus sonhos no documentário, referiu que gostaria de ter sua casa própria, estar casado, ter um carro e ter um serviço. No momento da pesquisa, ele percebeu que conseguiu realizar vários deles, pois já havia conquistado a casa própria, um emprego, está casado e já tem filhos. Relatou que sua companheira tem um papel fundamental em sua vida, sendo a principal incentivadora de seus sonhos. Na entrevista, Marcos afirma que gostaria que cada pessoa tivesse sua casa, trabalho e dez mil reais para não passar fome.

\section{Percurso de Ítalo}

Ítalo é um jovem de 19 anos e estava com 15 no momento do documentário. As informações sobre a trajetória de Ítalo foram obtidas por meio de contato com a avó do 
jovem, que será chamada de Elisa. Quando foi realizado o contato com ela, a mesma lembrou-se da participação do neto no documentário, o qual ela mesma já havia assistido. 0 impedimento do contato com Ítalo deu-se devido ao fato do mesmo encontrar-se em privação de liberdade por ter cometido um assalto, estar portando uma arma e haver se envolvido com drogas. Ítalo não estava recebendo visitas dos familiares e a família não possuía muitas notícias sobre o jovem.

Conforme relatos de Elisa, Ítalo não concluiu o Ensino Fundamental e cumpriu a medida socioeducativa de internação, ficando privado de liberdade por ter cometido um ato infracional ainda na adolescência, indicando uma trajetória permeada pela violência. Ainda, Elisa relatou, com muito pesar, a ocorrência de três mortes violentas na família: do pai, de um irmão e de uma irmã de Ítalo. Ela relata grandes conflitos no contexto familiar, o que inclui uma grave situação de violência sexual entre os irmãos já falecidos de Ítalo. A irmã teria sido violentamente estuprada por outro irmão, sendo que esse fato culminou na morte dela. Não foi possível o contato com a mãe de Ítalo, pois, segundo a avó, ela é alcoólatra e pouco permanece em casa.

\section{Resultados e discussões}

\section{A transição para a adolescência/juventude em contextos de vulnerabilidades}

Um dos aspectos a serem destacados com relação aos percursos de vida dos participantes diz respeito ao modo como compreendem a transição da adolescência e como percebem esse processo no contexto em que vivem. A reconfiguração da própria imagem e a transição, que implicam a inserção no mundo de um modo adulto, podem ser consideradas como passos importantes, visto que incidem diretamente na dimensão identitária (Calligaris, 2000). De acordo com Schoen-Ferreira, Aznar-Farias e Silvares (2003) a construção da identidade pode ser influenciada por fatores intrapessoais, fatores interpessoais e por fatores culturais, evidenciando que essa adolescência será constituída mediante o entrelaçamento de todos esses aspectos. 
Os jovens desta pesquisa refletem sobre esse processo de transição, tanto no momento do documentário quanto no momento das entrevistas. Contudo, essa transição, segundo os relatos dos participantes, acontece como um processo que entendemos não ser demarcado apenas pela idade cronológica, mas pela possibilidade de acomodação ou elaboração dos desafios psíquicos que se impõem. Eles referem estar ainda elaborando as novas responsabilidades que decorrem dessas transformações:

Eu acho que adolescente gosta de jogar bola, gosta de sair, gosta de ficar com a gurizada e eu não. Eu acho que eu não faço nada, é difícil fazer alguma coisa que um adolescente faz [...] Na verdade, eu me considero ainda um pouquinho adolescente, mas eu tenho vontade de estudar, tenho vontade de andar com os amigos ainda, quem não tem, né?! (Marcos, em 2016)

A partir da fala de Marcos, depreende-se a existência de certa ambivalência em relação a como ele se vê, ora sentindo-se como adolescente, ora como adulto. De fato, os processos de reconfiguração da imagem e de ingresso no mundo adulto compreendem importantes transformações no seu percurso de vida. Contudo, cabe questionar se o fato de reconhecer-se pouco como adolescente não traz à tona a autonomia e a independência características do mundo adulto, adquiridas de maneira mais urgente devido ao desemparo e a desproteção muitas vezes vivenciada nesse contexto (Waperchowski \& De Conti, 2018). Nesse sentido, é possível entender que as transformações adolescentes - tanto a entrada na adolescência, seu processo e sua saída - podem ser ainda mais "bruscas" e repentinas no cenário da vulnerabilidade social.

As repercussões dessas transformações podem ser tão significativas que, como se observa na fala de André na ocasião do documentário, o mesmo referiu ter receio sobre o que o futuro Ihe reservaria. Assim, em 2012, quando foi questionado sobre o seu crescimento, referiu que preferia ser criança, pois em sua percepção: "Quando eu crescer, não vai dar certo a coisa. Então, eu prefiro ser pequeno, ser assim, e aproveitar. Aproveitar o que eu tenho e não depender dos outros" (André, em 2012).

Essa fala traz as representações que os processos de amadurecimento podem assumir em contextos de vulnerabilidades sociais. Ao se compreender a vulnerabilidade 
social enquanto uma posição de desvantagem frente aos direitos que deveriam ser garantidos para determinadas populações, torna-se compreensível o caráter até mesmo assustador que o ingresso na vida adulta pode assumir. Depreende-se, assim, que as transformações colocadas com a experiência de passagem para a vida adulta, nesses contextos, podem trazer algumas peculiaridades aos atravessamentos desse fenômeno. A partir do caráter longitudinal do estudo, foi possível constatar que André manteve a percepção das vantagens que uma condição mais infantil fornece:

Antes, eu era de menor, antes, era com responsável. Agora, eu sou de maior, eu tomo as minhas atitudes [...]. Ser criança dá pra fazer um monte de coisa, dá pra brincar, dá pra fazer um monte de coisa, de maior não. De maior tem que ter mais responsabilidade com as coisas. Um monte de coisa [...], tipo, eu sou e não sou. Eu sou adolescente e não sou [...] Não sou véio e não sou novo [...] Tô naquelas. (André, em 2016)

Já a jovem Juliana, em 2016, ao se referir sobre esse mesmo aspecto, mencionou: "Eu não posso me considerar adulta porque eu não sou, né?! Mas, tipo, posso me considerar uma adolescente, mas, tipo, diferente de muitas, entendeu? [...] Eu já penso diferente, entendeu? Mais pra frente assim".

Nesse trecho, é evidenciada a ambivalência, também presente no relato de Juliana, como uma experiência importante de ser vivenciada nessa etapa da vida. Conforme salienta Kehl (2008), o portal de entrada para a vida adulta reflete para um "tempo de incertezas" (p. 48), em que se faz presente o medo de se entrar pela "porta errada". Para isso, há de se considerar a oferta e exaltação pelo uso de drogas, a banalização do tráfico no país, assim como pelo acesso facilitado às bebidas alcoólicas, ou ainda, por meio da delinquência, aspectos que afetam duramente aqueles que se encontram em situação de maior vulnerabilidade social.

O relato dessa participante evidencia a ênfase da jovem em querer se demonstrar diferente, colocando-se de forma distinta dos demais. Cabe ressaltar que o desejo de se situar no mundo, de forma única, constitui essa experiência de transição, própria da 
adolescência. Contudo, para além desse trecho, em diversos momentos da entrevista observou-se que Juliana se denominava como alguém "mais pra frente" que os demais amigos e com atitudes que a colocariam em uma condição diferenciada. Constata-se, com isso, um esforço por parte de Juliana em afirmar que, em seu contexto de vida atual, haveria um afastamento das dificuldades que estariam colocadas no contexto de vulnerabilidades em que se encontra, sendo esse um aspecto marcante de sua fala. Percebeu-se, assim, a importância para Juliana de afirmar ter sido resistente às dificuldades que se apresentaram em seu percurso, durante essa etapa de sua vida.

Há de se considerar que, nos locais reconhecidos pela vulnerabilidade social, a exclusão e a estigmatização também reforçam essa condição, havendo necessidade de atuação de políticas públicas para fortalecer a capacidade dos indivíduos, famílias e regiões, visando esse enfrentamento (Nascimento \& Melazzo, 2013). Possivelmente, a ênfase dada por Juliana ao se considerar "mais para frente" esteja associada à sua resistência de seguir em uma direção oposta ao que estaria naturalizado em seu contexto social marcado pela vulnerabilidade.

Karina também refletiu sobre sua adolescência, comparando os dois momentos de vida, por meio do documentário e da entrevista. Quando questionada sobre como era a sua adolescência, disse: "Olha, não vou dizer que era... Que era boa...Boa! Até porque eu saía toda hora em festa [...] Antigamente era massa ir. Era legal ir nas festa, não tinha briga, não tinha nada. Hoje, agora, tem" (Karina, em 2016).

A partir disso, Karina referiu, no momento da entrevista, que não vai mais a festas, relatando uma experiência de violência presenciada em um determinado momento de sua adolescência:

Teve uma vez que eu fui numa festa perto de casa [...] Que tava dando tiroteio nessa festa. Aí ele [irmão] começou a me puxar [...] Aí ele deu um tapa... Deu um tapa na cara das minhas prima. Aí chegou os home [polícia]. Os home deram um tunda de pau nele. (Karina, em 2016)

Pode-se relacionar a fala de André, sobre o receio de crescer e à possibilidade do "não dar certo", ao relato de Juliana enfatizando aquilo que considera ser "pra frente" e 
também ao presente enunciado de Karina, estabelecendo possíveis semelhanças nas experiências adolescentes vividas. A violência, o medo, a insegurança e o desamparo permeiam de forma incisiva o percurso adolescente e a transição para a vida adulta. Desse modo, cabe refletir também sobre os desdobramentos que esse cenário de vulnerabilidades apresenta para a vida desses jovens, isto é, de que forma transcorreram seus percursos de vida em meio aos diversos eventos e situações que puseram à prova a resistência dos mesmos.

\section{Os atravessamentos das vulnerabilidades em seus percursos de vida}

A partir das entrevistas realizadas e do caráter longitudinal do estudo, foi possível perceber que os percursos de vida dos participantes foram marcados por diversas vulnerabilidades. Além disso, no caso dos participantes deste estudo, essas vulnerabilidades parecem estar estreitamente relacionadas a situações de violência, as quais foram abordadas no decorrer das entrevistas e podem ser compreendidas como o pano de fundo de suas trajetórias. Essa condição de lidar com os atravessamentos para a superação das vulnerabilidades existentes estaria presente na fala de André, ao referir sobre a sua mudança de bairro no período entre o documentário e a entrevista: "Nós moremo lá naquela vila, se criemo. Que que adianta a gente sair da vila se a vila não vai sair de nós?" (André, em 2016).

Esse trecho explicita que, embora tenha ocorrido uma mudança de espaço físico, não houve mudança no que poderia ser entendido como seu espaço de pertencimento simbólico. Esse episódio da vida de André foi relatado na entrevista como uma mudança negativa, na medida em que André refere um sentimento de familiaridade, aproximação e identificação com o bairro de origem, onde residiu a maior parte da sua vida. Isto é, pode-se inferir que o local ao qual foi pertencente integrou de forma muito significativa a construção da sua identidade, no sentido de que, independentemente do espaço ou local onde estiver, esses aspectos serão levados consigo, constituindo a pessoa que André se tornou. 
Por outro lado, Marcos identificou a mudança de localização geográfica no que se refere ao endereço de moradia, como um aspecto positivo em seu percurso de vida, pois segundo ele: "Eu tô num paraíso, graças a Deus, lá onde eu moro é um paraíso!" (Marcos, em 2012).

Residindo em outro bairro no momento da entrevista, ele descreve o antigo bairro em que viveu a sua adolescência, da seguinte forma:

Não favela, mas é quase igual, sabe? [...] Imagina tu morar numa vila e acordar cedo pra tu pegar o ônibus pra ir pra faculdade, tá? E tu passa assim na frente da casa de duas ou três pessoas, e tem uns cara bem assim, que tão com aquela arma na mão, entendeu? Chegam assim e te perguntam: 'tu tem um real pra me dar?' Tu tem que abrir tua bolsa, tu tem que tirar, procurar um real pra dar pra ele e se tu não tem um real, não param de conversar e se tu dizer, 'bah, eu não tenho um real, tenho que ir lá, por favor, to atrasado', 'não, não, fica aí, tu tem que conversar comigo'. Eles te obrigam a aquilo, entendeu? [...] Era quase todo dia assim. (Marcos, em 2016)

Assim, a percepção de Marcos em relação à mudança parece estar relacionada à alteração de um contexto de violência para outro menos violento, ou seja, com menor exposição a contextos de vulnerabilidades. Ele salientou, em diversos momentos, a importância de conquistar a sua casa própria, partindo da ideia de se estabelecer em um local que oferecesse um contexto de vida diferente do que lhe foi apresentado no bairro onde residiu na maior parte de sua vida. Para Marcos, ter conquistado esse importante sonho parece representar a saída de uma realidade, com a qual ele dizia não se identificar, ainda que tenha sido determinante na construção do seu percurso de vida. Em diversos momentos da entrevista, o jovem manifestou a sua satisfação em ter alcançado metas que havia traçado para sua vida, as quais estavam registradas na sua participação no documentário e que foram relembradas no momento da entrevista, como mostra o seguinte fragmento: "O terreno também é próprio, com escritura e tudo. Foi difícil de pagar?! Foi, mas eu paguei. Trabalhando, todo dia trabalhando, de noite trabalhando também, o dia inteiro, mas paguei" (Marcos, em 2016). 
Essa fala de Marcos pode ser entendida como uma espécie de desabafo sobre o intenso esforço e as dificuldades pelas quais passou para que fosse possível concretizar o sonho que traçou. O conceito de vulnerabilidade social está vinculado ao de mobilidade social, uma vez que as possibilidades de movimentação nas estruturas sociais e econômicas são restritas, no que se refere à modificação da inscrição social já colocada (Guareschi, Reis, Huning, \& Bertuzzi, 2007). Dessa forma, sabe-se que a conquista da casa própria é uma realidade que não faz parte da vida da maioria dos jovens brasileiros que vivem em contextos de vulnerabilidade social, pois os mesmos não conseguem encontrar espaço em um sistema que fomenta tantas desigualdades.

De acordo com Ribeiro e Vóvio (2017), parte das populações distancia-se do valor democrático da mobilidade social, tanto em termos reais, no que diz respeito a uma mobilidade física, quanto em termos simbólicos, no que concerne às expectativas de melhoria do bem-estar social. Nesse ínterim, faz-se possível compreender a tamanha satisfação de Marcos em querer compartilhar e detalhar sobre os enfrentamentos vividos para conquistar os seus sonhos, os quais já estavam presentes desde o documentário. Assim, novamente, foi possível constatar neste contato com o jovem, um movimento na direção de salientar suas realizações pessoais, bem como de realçar o seu afastamento do contexto de violências.

Logo, o conceito de "fronteira" também pode adquirir importância especial nessa discussão, pois este, conforme descreve Augé (2010), é empregado "para dar um sentido ao mundo e torná-lo habitável" (p. 19). Nesse caso, não se trata de uma fronteira natural ou física, mas de uma fronteira simbólica, social e cultural. Logo, as fronteiras em contextos vulneráveis, cujas realidades são a da violência e da exclusão social, sustentam o sentido dessa realidade, resguardam e organizam ao seu modo um determinado funcionamento. $\mathrm{O}$ autor afirma também que "as fronteiras não se desfazem jamais, elas se redesenham" ( $p$. 25), apontando para o fato de que a realidade também se redesenha com o movimento das relações que traçam essas linhas simbólicas. Contudo, em sua perspectiva, essas linhas 
ganham força por meio do medo e da insegurança das pessoas em ultrapassá-las, conforme se pode observar nos seguintes relatos:

A gente queria ir embora, a gente não pôde, porque ele [ex-namorado] não queria que saísse da banda... E tipo... E como que eu ia ir sem a minha mãe embora, ia deixar ali? [...] É, tipo, é gangue, entendeu? [...] O cara era vida loca, me mandava, todo mundo tinha medo dele na banda, entendeu? Aí pegava... Tu acha que alguém ia afrontar? Ninguém afrontava, entendeu? (Juliana, em 2016)

No ano novo, eu tive que passar dentro de casa, né, com a minha família, porque eu não podia sair de casa, porque os vizinhos brigando, entendeu? Na frente do portão, tiro, briga. Então, tipo assim, não foi nada bom (Marcos, em 2016)

Naquele tempo, quando eu vinha no colégio, eu tinha bastante briga com piá, assim onde eu morava, entendeu? Eu acabei faltando muita aula por causa disso, que eu não podia passar num lugar, tinha que fazer toda a volta, era muito longe, entendeu? (Marcos, em 2016)

A partir desses relatos, pode-se perceber a existência dessas fronteiras simbólicas, sociais e culturais que cerceiam a liberdade dos participantes, impedindo-os de realizarem atividades específicas ou irem até locais de seus interesses. Além disso, a violência no território das periferias e a delimitação de fronteiras também podem perpassar relações, como pode ser observado na fala de Juliana sobre a não aceitação do término do seu relacionamento por parte de seu ex-namorado: “[Ele] Tem vários 'cupincho', aí ia fechar os quatro cantos da vila e eu não podia sair" (Juliana, em 2016).

Pode-se inferir aqui, a partir do relato de Juliana, o papel de liderança, poder e domínio ocupado pelo ex-namorado da jovem, dentro do território, evidenciando a existência de funcionamentos e leis próprias, que correspondem àqueles que convivem e compartilham desse espaço. Logo, essas fronteiras parecem estar sempre demarcadas pela presença da violência, que seria um elemento organizador das relações e da mobilidade.

A partir dessas discussões, entende-se que há certas especificidades nos contextos em que vivem e circulam esses jovens, como a localização em regiões periféricas da cidade e a violência nelas presente. Por conta disso, esses territórios encontram-se marginalizados, 
não só por estarem fisicamente situados às margens da cidade, mas, também, por se encontrarem nas "margens" da sociedade - afastados do núcleo de consumo e de inclusão social. Segundo Porto (2000), aqueles que convivem em contextos de exclusão social (compreendendo também as questões territoriais) tornam-se alvos ou atores mais imediatos da violência. Nessa perspectiva, Novaes (2006) aponta para a discussão de que certos endereços carregam consigo, automaticamente, estigmas de áreas urbanas subjugadas pela violência. Esses espaços são reconhecidos como favelas, subúrbios, vilas, periferias, morros, conjuntos habitacionais, comunidades, entre outros, e estão, no imaginário social, atrelados a representações negativas.

Nesse sentido, a vulnerabilidade social, a precária infraestrutura urbana e a insuficiência do Estado no que tange às políticas públicas criam um cenário propício ao estabelecimento de grupos que podem estar envolvidos em situações violentas. Tais grupos, em especial os que lidam com o tráfico de drogas, podem ser considerados como agentes que se territorializam e atuam sobre determinado espaço. Uma vez territorializados, em geral nos bairros periféricos, podem aderir a atividades ilícitas, como a venda de drogas, interferindo no cotidiano da população local e gerando sensações de medo e de insegurança (Borges, Nascimento, Vieira, \& Andrade, 2016). Isso acaba por reforçar estigmas e preconceitos sobre a população pertencente a esses territórios, que por vezes se tornam reconhecidos de forma negativa por outras comunidades e instituições. No contato com a avó de Ítalo, ela referiu que o jovem não concluiu o Ensino Fundamental, pois teria começado a "se envolver com outras coisas", o que, no caso dele, estava relacionado ao contexto das drogas. $\mathrm{O}$ relato de André também elucida esses aspectos, quando ele refere: "Se eu tô junto com eles e a polícia bate, leva eu junto, sendo que eu não tenho nada a ver" (André, em 2016).

Além disso, o jovem afirma que, se tivesse uma varinha mágica, gostaria de ir embora da cidade, porque, conforme ele, ela está muito perigosa. Ele gostaria de ir morar com o tio em outra cidade. Esse tio mora no campo e, segundo ele: "É pra fora, lá não escuta 
nada. Só passarinho cantando [...] Isso é bom [...] Não passa carro, não passa gente" (André, em 2016).

A partir dessa configuração, Broide (2010) considera a periferia como uma instituição total, ou seja, sendo regida por um poder soberano que age na ausência da lei e faz o território ser tomado pela violência. Ressalta o autor que pensar a periferia como instituição total ajuda a entender a angústia e o medo que assolam os jovens e que poderiam dar um sentido à fala de André quando refere querer deixar a cidade e tudo que ela representa. Segundo o autor, a violência, no território da periferia, tem como consequência a manutenção do sujeito em alerta máximo, pois a qualquer instante ele pode ser engolfado em um acontecimento destrutivo. Com isso, instaura-se uma ação reativa que alimenta a violência em circuito fechado. A partir dessa perspectiva, pode-se pensar que morar para fora, como refere André, pode ser compreendido como um contexto de tranquilidade e paz, oposto ao território que se encontra, em sua percepção, permeado pela instabilidade e pela violência.

Nesse cenário, os jovens são, muitas vezes, tomados pelo medo, o que faz com que tenham que se tornar valentes e, por vezes, violentos, o que aprisiona esses sujeitos em um destino que parece inescapável. A partir disso, se pode compreender o desejo de André, o qual referiu que, se caso tivesse uma varinha mágica, iria embora da cidade. Talvez essa fosse para ele a única possibilidade de escapar do aprisionamento que as relações violentas presentes no território produzem, tal como as instituições totais, as quais se caracterizam por seu caráter de fechamento e de domínio da totalidade das esferas da vida. Tal como André, Marcos também se refere à saída do território, o que pode ser compreendido na mesma perspectiva, ou seja, como uma forma de escapar desse destino retroalimentado pela violência e que acaba marcando "a ferro e fogo" suas identidades.

Tal aspecto pode ser pensado em relação à vivência de Ítalo, não sob uma perspectiva reducionista de causa e efeito, mas como um entre diversos fatores interdependentes que teriam influência sobre seu percurso de vida. Foi nesse contexto que sua avó relata terem acontecido as mortes por assassinato do pai e do irmão. Isso parece, mais uma vez, reforçar o medo e a insegurança que pairam sobre esses territórios, 
impulsionando aqueles que ali constroem seus percursos a sonharem com realidades diferentes e distantes, exercitando o limite das fronteiras da exclusão que tão fortemente se colocam para eles e que parecem ser tão difíceis de serem superadas. Destaca-se, com isso, a importância de um olhar que possa reconhecer os atravessamentos da vulnerabilidade social na construção do ser adolescente e na transição para a vida adulta, além de ações governamentais que possam ampliar oportunidades de inserção e pertencimento para romper ciclos excludentes e violentos, assegurando direitos para todos os jovens.

\section{Considerações finais}

Tendo-se presente a força da periferia e considerando que a maior parte dos jovens brasileiros circula por territórios que, marcados pela vulnerabilidade, têm proximidade com os aqui evidenciados pelos participantes, é extremamente importante pensar como trabalhar, discutir e qualificar as experiências vivenciadas nesse contexto. Valorizar esse espaço pode se converter numa saída interessante para evitar que eles sejam reconhecidos a partir de uma dimensão negativa, ou que os jovens venham a encontrar a violência como estratégia de enfrentamento aos desafios impostos pelo contexto em que vivem e no qual constroem suas relações.

Destaca-se também que o fato de o estudo ter sido realizado em uma Escola Aberta possibilita a reflexão de que a Escola é também um espaço onde, em alguma medida, encontram-se atenuadas as desigualdades e os preconceitos, um espaço no qual se sentem iguais e, por isso, em certa medida se converte em um contexto protetivo. Por outro lado, o fato de a Escola atender somente a um público que claramente advém de contextos estigmatizados acaba tornando-a um espaço exclusivo, que pode gerar certo constrangimento simbólico, ainda que vise à inclusão social.

Nesse sentido, ressalta-se a importância de ampliar iniciativas e políticas públicas voltadas para esse público, que estejam em conformidade com as legislações vigentes para a 
população jovem no país. Ainda, é preciso quebrar as barreiras do estigma e do preconceito sobre as periferias, não as reconhecendo apenas como locais de violência, mas sim como locais de potencialidades, de cultura, de pertencimento, de constituição identitária e de afetos. Destaca-se a necessidade de políticas públicas, pensadas e articuladas em consonância com as demandas e características dos diferentes territórios. Ações e intervenções que estejam desconectadas dos contextos e das próprias marcas deixadas por eles nas diferentes trajetórias de vida podem não ser efetivas e resolutivas, dada a grande repercussão que parecem ter, em especial neste estudo, para o público adolescente/jovem.

Entendendo a complexidade do tema, do contexto social e da população em questão, não se pretendeu, neste estudo, esgotar as possibilidades e temáticas nesse âmbito. Portanto, sugere-se a realização de outros estudos, discussões e intervenções, a fim de compreender melhor esse contexto e contribuir para a construção de novos olhares para essa questão.

Por último, é importante destacar a relevância do caráter longitudinal desta pesquisa, tendo em vista que, muitas vezes, acessar jovens que estão inseridos nesses contextos de vulnerabilidade social torna-se mais difícil, pois seu cotidiano se encontra permeado por situações que podem impedir com que eles sejam contatados novamente, pelas dificuldades em localizá-los, pela instabilidade que caracteriza o cotidiano nesse contexto e pelas situações de violência que podem ter atravessado seus percursos. Entretanto, poder escutar esses jovens novamente amplia as possibilidades de compreensão de seus percursos de vida e dos desdobramentos das vulnerabilidades em suas trajetórias, nos possibilitando melhor compreendê-los e, com isso, agir no sentido de superar e transpor essas barreiras e seus efeitos.

\section{Referências}

Abramovay, M. et al. (2002). Juventude, Violência e Vulnerabilidade Social na América Latina: desafios para as políticas públicas. Brasília, DF: UNESCO, BID.

Arpini, D. M. (2003). Violência e exclusão: adolescência em grupos populares. Bauru: EDUSC. 
Arpini, D. M., \& Witt, C. S. (2015). As múltiplas formas de ser adolescente. In H. R. Campos, \& S. M. G. Sousa (Orgs.), Emocore: experiências grupais na constituição da adolescência (pp. 11-28). Natal: EDUFRN; Goiânia: Editora PUC Goiás.

Augé, M. (2010). Por uma antropologia da mobilidade. Maceió: EDLTFAL: UNESP.

Bardin, L. (2010). Análise de conteúdo. Lisboa: Edições 70.

Borges, R. H. M., Nascimento, R. P. B. do, Vieira, D. C. M., \& Andrade, L. C. M. (2016). Território, Violência e Criminalidade: uma análise geográfica sobre os índices de homicídios no bairro do PAAR em Ananindeua-PA. Anais XVIII Encontro Nacional dos Geógrafos (pp. 1-12). São Luís: Universidade Federal do Maranhão. http:/ / www.eng2016.agb.org.br/resources/anais/7 / 1468267933_ARQUIVO_TrabalhoEng-Rafael,Robson,DeniseeLucas.pdf

Brasil, República Federativa do Brasil. (1990). Lei $n^{\circ}$ 8.069, de 13 de julho de 1990. Dispõe o Estatuto da Criança e do Adolescente e dá outras providências. Brasília, DF: Presidência da República. http://www.planalto.gov.br/ccivil_03/leis/L8069.htm

Brasil, República Federativa do Brasil. (2013). Lei $n^{\circ}$ 12.852, de 5 de agosto de 2013. Institui o Estatuto de Juventude e dispões sobre o direito dos jovens, os princípios e diretrizes das políticas de Juventude e o sistema Nacional de Juventude - SINAJUVE. Brasília, DF: Presidência da República. http://www.planalto.gov.br/ccivil_03/_ato20112014/2013/lei/l12852.htm

Brasil, República Federativa do Brasil. Ministério da Saúde. Conselho Nacional de Saúde. (2016). Resolução 510/2016. Diretrizes e normas regulamentadoras de pesquisas envolvendo seres humanos. Brasília, DF: Ministério da Saúde.

Broide, J. (2010). Psicanálise: nas situações sociais críticas. Violência, juventude e periferia: em uma abordagem grupal ( $1^{\text {a }}$ reimpr.). Curitiba: Juruá. (Obra original publicada em 2008)

Calligaris, C. (2000). A adolescência. São Paulo: Publifolha. 
Carmo, M. E., \& Guizardi, F. L. (2018). O conceito de vulnerabilidade e seus sentidos para as políticas públicas de saúde e assistência social. Cadernos de Saúde Pública, 34(3), 1-14. http://doi.org/10.1590/0102-311×00101417

Castel, R. (1997). A dinâmica dos processos de marginalização: da vulnerabilidade a “desfiliação". Caderno CRH, 10(26), 19-40. http://doi.org/10.9771/ccrh.v1 0i26.18664

Cronemberger, I. H. G. M., \& Teixeira, S. M. (2013). Famílias vulneráveis como expressão da questão social, à luz da política de assistência social. Informe econômico, 1(1), 17-26. https://revistas.ufpi.br/index.php/economiaufpi/article/view/1267.

Cruz, L. R., \& Hillesheim, B. (2016). Vulnerabilidade Social. In R. M. C. Fernandes, \& A. Hellmann (Orgs.), Dicionário Crítico: Política de Assistência Social no Brasil (pp. 300302). Porto Alegre: Ed. UFRGS.

Gaskell, G. (2005). Entrevistas individuais e grupais. In M. W. Bauer, \& G. Gaskell (Orgs.), Pesquisa qualitativa com texto, imagem e som (pp. 64-89). Petrópolis: Vozes. https://lume.ufrgs.br/bitstream/handle/10183/198716/001 100774.pdf?sequence $=1 \& \mathrm{i}$ sAllowed $=y$

Guareschi, N. M. F., Reis, C. D., Huning, S. M., \& Bertuzzi, L. D. (2007). Intervenção na condição de vulnerabilidade social: um estudo sobre a produção de sentidos com adolescentes do programa do trabalho educativo. Estudos e Pesquisas em Psicologia, $7(1), \quad 17-27 . \quad$ http://pepsic.bvsalud.org/scielo.php?script=sci_arttext\&pid=S1808$42812007000100003 \& \operatorname{lng}=p t \&$ lng $=p t$

Janczura, R. (2012). Risco ou vulnerabilidade social? Textos \& contextos, 11(2), 301-308. http://revistaseletronicas.pucrs.br/ojs/index.php/fass/article/view/12173

Kehl, M. R. (2008). O risco adolescente. In M. R. Kehl (Org.). A fratria órfã: conversas sobre a juventude (pp. 48-50). São Paulo: Olho d’Água.

Kemper, M. L. C. (2013). Invisibilidade, identidade e laço social na contemporaneidade: sobre a exclusão na esfera psíquica e social. Caderno Psicanálise, 35(29), 105-125. http:// pepsic.bvsalud.org/scielo.php?script=sci_abstract\&pid=S1413$62952013000200007 \& \operatorname{lng}=\mathrm{pt} \& \mathrm{nrm}=\mathrm{iso}$ 
Klautau, P. (2017). O método psicanalítico e suas extensões: escutando jovens em situação de vulnerabilidade social. Revista Latinoamericana de Psicopatologia Fundamental, 20(1), 113-127. https://doi.org/10.1590/1415-4714.2017v20n1 p1 13.8

Matheus, T. C. (2010). Adolescência: história e política do conceito na psicanálise. São Paulo: Casa do Psicólogo.

Monteiro, S. R. R. P. (2011). O marco conceitual da vulnerabilidade social. Sociedade em Debate, 17(2), 29-40. http://www.rsd.ucpel.tche.br/index.php/rsd/article/view/695

Nascimento, P. F., \& Melazzo, E. S. (2013). Território: conceito estratégico na assistência social. Serviço Social em Revista, 16(1), 66-88. http://doi.org/10.5433/1679$4842.2013 \mathrm{v} 16 \mathrm{n} 1 \mathrm{p} 66$

Novaes, R. (2006). Os jovens de hoje: contextos, diferenças e trajetórias. In M. I. Almeida, \& F. Eugenio (Orgs.), Culturas jovens: novos mapas do afeto (pp. 105-120). Rio de Janeiro: Jorge Zahar Editora.

Oliveira, C. (2001). Sobrevivendo no inferno. Porto Alegre: Ed. Sulina.

Osório, L. C. (1989). Adolescente hoje. Porto Alegre: Artes Médicas.

Porto, M. S. G. (2000). A violência entre a inclusão e a exclusão social. Tempo Social, 12(1), 187-200. http://doi.org/10.1590/S0103-20702000000100010

Ribeiro, C. M., \& Vóvio, C. L. (2017). Desigualdade escolar e vulnerabilidade social no território. Educar em revista, 2(1), 71-87. https://doi.org/10.1590/0104-4060.51372

Rosa, M. D. (2016). A clínica psicanalítica em face da dimensão sociopolítica do sofrimento. São Paulo: Escuta/Fapesp.

Schoen-Ferreira, T. H., Aznar-Farias, M., \& Silvares, E. F. M. (2003). A construção da identidade em adolescentes: um estudo exploratório. Estudos de Psicologia, 8(1), 107115. https://doi.org/10.1590/S1413-294X2003000100012 
Warpechowski, M. B., \& De Conti, L. (2018). Adolescer em contextos de vulnerabilidade e exclusão social. Estilos Clínicos, 23(2), 322-343. https://doi.org/10.11606/issn.19811624.v23i2p322-343

Recebido em: 10/8/2018

Aprovado em: 3/4/2020 